Análisis. Revista de investigación filosófica, Vol. 1, nº 1, 2014, pp. 1-23

\title{
NATURALISMO SIN REPRESENTACIONALISMO ${ }^{1}$
}

\author{
Huw Price
}

\section{LA RELEVANCIA DE LA CIENCIA PARA LA FILOSOFÍA}

¿Qué es el naturalismo filosófico? Fundamentalmente, y presumiblemente, es la concepción según la cual la ciencia natural constriñe a la filosofía en el siguiente sentido: las preocupaciones de las dos disciplinas no están desconectadas sin más, y es la ciencia la que toma las riendas cuando ambas se solapan. Por tanto, ser un naturalista filosófico supone, como mínimo, creer que la filosofía no es simplemente una empresa diferente a la ciencia y, además, que la filosofía se somete a la ciencia allí donde las preocupaciones de ambas disciplinas coinciden.

Un naturalismo tan básico como este no es de ningún modo trivial. No obstante, gran parte de la oposición al naturalismo en la filosofía contemporánea no se opone exactamente a este naturalismo tan básico, sino a una concepción más específica de la relevancia que tiene la ciencia para la filosofía. Lo mismo ocurre en las filas pro-naturalistas. Lo que la mayoría de aparentes naturalistas tienen en mente es la concepción más específica. Opino que, como consecuencia de ello, ambas partes del debate contemporáneo prestan una atención insuficiente a otra clase de naturalismo filosófico -una concepción diferente del impacto que tiene la ciencia sobre la filosofía-. Esta otra concepción no es, ciertamente, novedosa -ha estado con nosotros al menos desde Hume-, pero tampoco está presente en muchos debates contemporáneos.

En este trabajo intentaré remediar esta situación. Comenzaré haciendo buena la afirmación de que la posición comúnmente llamada naturalismo no es un corolario necesario del naturalismo en el sentido básico esbozado arriba.

\footnotetext{
${ }^{1}$ Traducción del artículo "Naturalism Without Representationalism” de Huw Price, reimpreso con permiso del editor de NATURALISM IN QUESTION, editado por Mario De Caro y David Macarthur, pp. 71-88, Cambridge, Mass.: Harvard University Press, Copyright (C) 2004 by the President and Fellows of Harvard College. Traducción de David Pérez Chico.
} 
Hay dos maneras muy distintas entre sí de entender qué quiere decir que la ciencia sea relevante para la filosofía. Y, quizás contrariamente a la primera impresión, las implicaciones más importantes que estas dos concepciones tienen para la filosofía surgen de un mismo punto de partida. Existe una determinada clase de problemas básicos para los que las dos clases de naturalismo ofrecen respuestas bien distintas.

Defenderé que la concepción menos conocida es, en un sentido que habrá que explicar, más fundamental que su rival; y que al llamar la atención sobre la diferencia entre ambas, estamos llamando la atención sobre una profunda dificultad estructural que se le presenta a la segunda. Defenderé, por lo tanto, el naturalismo en la que pienso que es su forma más fundamental, al mismo tiempo que criticaré su manifestación contemporánea más popular.

Tanto la dificultad de la concepción popular como la prioridad de su rival menos popular dependen del papel fundacional de ciertas presuposiciones "semánticas" o "representacionalistas" por parte del naturalismo de la clase popular. En mi opinión, este papel no acaba de ser bien entendido, pero posee en sí mismo un interés considerable (merece ser examinado en mucho más detalle del que yo puedo ofrecer en este trabajo). En relación con mis objetivos su importancia descansa sobre cuatro hechos. Primero, las presuposiciones implicadas no son obligatorias y representan una encrucijada crucial para el naturalismo -si se rechazan, se rechaza el naturalismo de la variedad popular-. Segundo, el punto de vista desde el que se decide correctamente qué dirección tomar es el del naturalismo de la variedad impopular -este es el sentido en el que esta clase de naturalismo es conceptualmente anterior a su pariente más popular-. Tercero, la posibilidad de que se rechacen estas suposiciones no es una mera amenaza vacía, sino que se trata de un corolario de algunas concepciones filosóficas contemporáneas destacadas. Y cuarto, y éste es potencialmente el más grave de todos, las suposiciones resultan ser dudosamente aceptables si se tienen en cuenta los estándares de la clase de naturalismo que se suponía que ellas mismas debían sostener.

Con respecto al naturalismo, por lo tanto, mi argumento es más o menos como sigue. Para poder valorar las perspectivas del naturalismo filosófico necesitamos disponer de un sentido claro de cuál es la tarea de la filosofía en aquellas áreas en las que, concebiblemente, la ciencia puede ser relevante. Arrojar claridad sobre esta cuestión revela no solo que la aproximación comúnmente denominada naturalismo no es la única opción filosófica sensible en estas áreas a la ciencia, sino también que una 
aproximación diferente es la aproximación preeminente en los distintos sentidos ya comentados. Si se entiende que esto son malas noticias para los naturalistas contemporáneas de la clase ortodoxa, quizá pueda pensarse que se trata de buenas noticias para los no naturalistas contemporáneos. Pero espero que quede finalmente claro que mis intenciones son mucho más imparciales. Muchos no naturalistas comparten las presuposiciones representacionalistas de sus oponentes naturalistas y al cuestionar esas presuposiciones, estamos cuestionando las dos partes del debate que dichas presuposiciones sostienen. Así pues, me opongo tanto al naturalismo popular como al no naturalismo popular y favorezco una clase diferente de naturalismo - un naturalismo sin representacionalismo-.

\section{Dos Clases De NATURALISMO.}

La clase popular de naturalismo -la que menudo se conoce simplemente como "naturalismo"- existe tanto en una versión ontológica como en una epistemológica. En tanto que doctrina ontológica, se trata de una concepción para la que, en un sentido importante, todo lo que bay es el mundo estudiado por la ciencia. Y en tanto que doctrina epistemológica, se trata de una concepción para la que el único conocimiento genuino es el conocimiento científico. $^{2}$

Llamaré a esta concepción naturalismo del objeto. A pesar de que es ampliamente aceptado en la filosofía contemporánea, muchos de sus seguidores coinciden con algunos de los críticos que opinan que este naturalismo conduce a algunas dificultades considerables. Esta concepción implica que si la filosofía está interesada en la naturaleza de objetos y propiedades de distintos tipos, entonces su interés está dirigido o bien hacia el mundo natural o hacia ninguna parte, puesto que simplemente no hay nada más. Quizás existan otras maneras diferentes de hablar del mundo-que-estudiala-ciencia -diferentes "modos de presentación" de aspectos de la misma realidad natural-, pero el objeto de cada manera de hablar es un aspecto del mundo-que-estudia-la ciencia o, de lo contrario, no es nada. Las dificultades surgen del hecho de que en muchos casos interesantes es difícil ver de qué hechos naturales podríamos estar hablando. Diferentes personas ofrecerán

${ }^{2}$ Una cuestión delicada es la de si existe alguna diferencia relevante entre estas dos versiones de naturalismo, pero se trata de una cuestión que ignoraré en este trabajo. 
listas diferentes de estos "problemas difíciles" -entre los candidatos habituales encontramos, por ejemplo, el significado, los valores, la verdad matemática, la causación y la modalidad física, y varios aspectos de la mente-, pero es prácticamente un lugar común en la filosofía contemporánea, para ambas partes del debate entre naturalistas y sus oponentes, que la lista no está vacía.

En breve diré algo más sobre estas cuestiones -las llamaré problemas de la localización-, pero antes de hacerlo quiero distinguir el naturalismo del objeto de una segunda concepción sobre la relevancia que tiene la ciencia para la filosofía. Según esta segunda concepción la filosofía debe comenzar por lo que la ciencia nos dice acerca de nosotros mismos. La ciencia nos dice que los seres humanos somos criaturas naturales, y si las pretensiones y las ambiciones de la filosofía chocan con esta aseveración, entonces la filosofía debe hacerse a un lado. Este es, así pues, el naturalismo en el sentido de Hume y, opinablemente, el de Nietzsche. ${ }^{3}$ Lo denominaré naturalismo del sujeto.

¿Cuál es la relación entre el naturalismo del objeto y el naturalismo del sujeto? A primera vista, puede parecer que el segundo no es más que un corolario obvio del primero. Los "naturalistas" contemporáneos -naturalistas del objeto, según mi propia denominación- seguramente insistirán en que ellos también son naturalistas del sujeto. Después de todo, si todas las entidades reales son entidades naturales, seguramente los seres humanos también seremos entidades naturales. Pero, en mi opinión, la relación entre las dos aproximaciones es mucho más interesante. En un sentido muy importante el naturalismo del sujeto es anterior.

Quiero defender la siguiente afirmación:

Tesis de la prioridad: El naturalismo del sujeto es teóricamente anterior al naturalismo del objeto porque el segundo depende de una validación que se realiza desde la perspectiva del naturalismo del sujeto.

¿Que significan "prioridad” y "validación” en este contexto? Tal y como apunté con anterioridad, el naturalismo del sujeto dirige su atención a la cuestión de la respetabilidad "científica" de las afirmaciones y presuposiciones de la filosofía -en particular, su compatibilidad con el reconocimiento de que

${ }^{3}$ Ambas atribuciones requieren ser justificadas. Como uno de los padres del empirismo, a Hume ciertamente le corresponde cierta responsabilidad por la concepción que el naturalismo del objeto tiene de la naturaleza del conocimiento. 
los seres humanos somos criaturas naturales-. Si la presuposición del naturalismo del objeto resulta ser sospechosa desde esta perspectiva científica auto-reflexiva, entonces el naturalismo del sujeto nos da razones para rechazar el naturalismo del objeto. Así pues, el naturalismo del sujeto es anterior y, concebiblemente, podría "invalidar" al naturalismo del objeto.

En mi opinión, esta amenaza para el naturalismo del objeto es muy real. También defenderé esta afirmación:

Tesis de la invalider: Existen poderosas razones para dudar de que el naturalismo del objeto merezca ser "validado" -de que sus presuposiciones sobrevivan al escrutinio del naturalismo del sujeto-.

Tal y como anuncié, mi defensa de esta afirmación dependerá del papel que ciertas presuposiciones "semánticas" y "representacionalistas" desempeñan en la fundamentación del naturalismo del objeto. Sin embargo, cuál sea el papel crucial de tales presuposiciones no está nada claro. Para hacerlo visible necesitaremos examinar antes la estructura de algunos casos reconocidos como difíciles para el naturalismo del objeto, los casos que he denominado problemas de la localización.

\section{LA CUESTIÓN DE LA LOCALIZACIÓN}

Si toda la realidad es en última instancia una realidad natural, ¿cómo debemos "localizar" en ella hechos morales, hechos matemáticos, hechos del significado, etc.?, ¿cómo localizaremos tópicos de estas clases en un marco naturalista? En casos como estos, parece que nos vemos obligados a elegir entre forzar el tópico en cuestión para que encaje en una categoría que por una razón u otra no parece adecuada para contenerlo, o considerarlo como mucho de segunda clase, esto es, no como un área o un hecho genuino de conocimiento.

Una manera de escapar de este dilema consiste en rechazar el naturalismo que lo provoca. Si el conocimiento científico no fuera el único conocimiento genuino, ni los hechos científicos los únicos hechos genuinos, entonces no sería necesario intentar meter a presión los casos problemáticos en los ropajes naturalistas. De heno, son los problemas de la localización los que espolean a una gran parte de la oposición contemporánea al naturalismo en filosofía. No obstante, existen dos maneras muy diferentes de rechazar la clase de naturalismo que da lugar a estos problemas. Una manera es ser no 
naturalista en la misma clave ontológica o epistémica -ser un no-naturalista del objeto, por así decir-. La otra manera consiste en ser naturalista en una clave diferente -rechazar el naturalismo del objeto en favor de una aproximación desde el naturalismo del sujeto a los mismos problemas teóricos-.

A primera vista, no parece quedar espacio conceptual para la segunda concepción, al menos en general, y al menos si queremos evitar un subjetivismo universal acerca de todos los casos difíciles. Porque el naturalismo del sujeto descansa sobre el hecho de que los humanos somos criaturas naturales, mientras que los problemas de la localización surgen en casos que no son, al menos de una manera obvia, humanos en su naturaleza. Todo esto es, sin embargo, muy apresurado. La posibilidad de una aproximación distintiva del naturalismo del sujeto a las cuestiones de localización giran sobre el hecho de que, opinablemente, estos problemas son en origen problemas acerca del uso lingüístico humano.

De hecho, resulta que hay dos concepciones posibles del origen de los problemas de la localización -dos concepciones de los "datos crudos" con los que la filosofía comienza en tales casos. Según una concepción, el problema comienza con datos lingüísticos (o puede que psicológicos); en el otro, comienza con los objetos mismos. Estas dos concepciones no siempre se distinguen con claridad, pero las diferencias entre ellas son muy importantes. Tal y como explicaré, la prioridad del naturalismo del sujeto y, por lo tanto, la vulnerabilidad del naturalismo del objeto, dependen de la tesis de que la concepción lingüística sea la concepción correcta.

\section{4. ¿DÓNDE COMIENZAN LOS PROBLEMAS DE LA LOCALIZACIÓN?}

A primera vista, el típico problema de la localización busca comprender cómo un objeto, una propiedad o un hecho cualquiera puede ser un objeto, una propiedad o un hecho natural. Dejando a un lado por ahora las diferencias que existen entre objetos, propiedades y hechos, la cuestión es, así pues, cómo una cosa $\mathrm{X}$ puede ser una cosa natural -la clase de cosa que es descubierta por la ciencia (al menos en principio)-.

¿Cómo surgen estas cuestiones en filosofía? Según una posible respuesta, el punto de partida es el objeto mismo. Así, simplemente estamos familiarizados con $\mathrm{X} y$, en un momento dado -movidos por un compromiso con el naturalismo del objeto-, nos preguntamos cómo puede esta cosa-con-laque-estamos-familiarizados pertenecer a la clase de cosas que estudia la ciencia.

Análisis. Revista de investigación filosófica, Vol. 1, n 1, 2014 
Según otra posible respuesta, el punto de partida reside en lo que, de manera general, podemos denominar prácticas lingüísticas humanas. En pocas palabras, observamos que los seres humanos (nosotros mismos u otros) emplean el término " $\mathrm{X}$ " en su lenguaje, o el concepto $X$ en su pensamiento. Movidos por un compromiso con el naturalismo del objeto nos preguntamos, de nuevo, cómo podría aquello que los hablantes dicen o piensan pertenecer a la clase de cosas estudiadas por la ciencia.

Llamemos a estas dos respuestas sobre el origen del problema de la localización la concepción material y la concepción lingüistica respectivamente. A favor de la concepción material podría esgrimirse que el problema de la localización para X es un problema acerca de la cosa X y no un problema acerca del término "X". En otras palabras, se trata del problema de cómo localizar a X en el mundo natural, y no del problema acerca de cómo localizar el término " $\mathrm{X}$ ".

Por otro lado, en favor de la concepción lingüística observamos que ciertos movimientos bien conocidos en los debates filosóficos que han sido motivados por el problema de la localización simplemente carecerían de sentido si asumimos la construcción material del problema. Consideremos el no-cognitivismo, que intenta evitar el problema de la localización mediante el argumento de que el discurso sobre $\mathrm{X}$-esto es, el uso estándar del término "X"no posee una función referencial o descriptiva. Aquí, la pretensión es que, a partir de una comprensión correcta del lenguaje implicado no habría ningún problema material. Por supuesto, el no-cognitivismo podría estar equivocado en determinados casos, pero si la concepción materialista del problema de la localización fuese correcta, no estaría simplemente equivocado sino completamente desencaminado -sería una concepción que sencillamente comienza en el lugar equivocado-. Ciertamente, es posible que el nocognitivismo esté desencaminado, pero el hecho de que esta no es la opinión generalizada revela la existencia de una aceptación implícita extendida de la concepción lingüística de la cuestión de la localización.

Esta apelación a la práctica filosófica, claro está, no pretende ser concluyente. En lugar de eso voy a proceder de la siguiente manera. De momento simplemente asumiré que la concepción lingüística es correcta y exploraré qué consecuencias tiene esto para el naturalismo del objeto (puntualmente recordaré a los lectores que mis conclusiones dependen de esta suposición). Al final del artículo retomaré la cuestión de si estamos obligados a hacer esta suposición -si el naturalismo del objeto puede evitar mis conclusiones críticas adoptando la concepción materialista-. Defenderé, 
aunque de manera tentativa, que no se trata de una opción real y que, por lo tanto, mis conclusiones previas no pueden ser evitadas de esta manera.

\section{LA ESCALERA SEMÁNTICA.}

Si la concepción lingüística es correcta, entonces los problemas de la localización serían inicialmente acerca del comportamiento lingüístico humano (o puede que acerca del pensamiento humano). ¿Qué convierte una preocupación semejante en una cuestión sobre otra cosa distinta -acerca de los valores, de la realidad matemática o lo que sea-? La respuesta a esta pregunta estaba implícita más arriba, cuando nuestra atención se desplazó del término a aquello acerca de lo que es. El desplazamiento descansa sobre lo que podríamos llamar la suposición representacionalista. Muy brevemente, se trata de la suposición de que los ítems lingüísticos en cuestión "significan" o "representan" algo no-lingüistico (al menos en general -dejemos a un lado por ahora el caso especial en el que el tema es lingüístico-). Esta suposición es el fundamento del desplazamiento de la atención desde el término "X" o desde el concepto $\mathrm{X}$, a su supuesto objeto $\mathrm{X}$.

A primera vista, sin embargo, la suposición requerida puede parecer trivial. ¿No es un truismo que " $\mathrm{X}$ " se refiere a X? ¿No es esto simplemente el análogo referencialista del hecho de que "la nieve es blanca" es verdad si y solo si la nieve es blanca?

En mi opinión la familiaridad con estos principios oculta una seria confusión. En verdad el movimiento en cuestión es en cierto sentido el conocido descenso semántico en el que una relación semántica -la de referencia, si tratamos con términos, o la de verdad si tratamos con enunciados- aporta la "escalera" que nos lleva desde una cuestión sobre el lenguaje a una cuestión sobre una realidad no lingüística. Pero es crucial ver que en nuestro caso, el movimiento implica un cambio real de foco teórico, un cambio real de tema. Se trata, por lo tanto, de un descenso lógico genuino y no de una mera inversión del "ascenso semántico" deflacionario quineano. El ascenso semántico quineano realmente nunca levanta el vuelo. El mismo Quine lo expresa de esta manera: "al llamar verdadera a la oración 'La nieve es blanca' llamamos blanca a la nieve. El predicado verdad es un dispositivo de desentrecomillado” (Quine, 1970, p. 12). Así pues, la escalera semántica deflacionaria de Quine nunca nos "sube", mientras que nuestra escalera semántica necesita llevarnos "abajo". 
En otras palabras, si comenzamos con las nociones semánticas deflacionarias de Quine, entonces hablar del referente del término " $\mathrm{X}$ ", o de la verdad de la oración "X es F", es únicamente una manera distinta de hablar del objeto X. De tal manera que si nuestra pregunta original era realmente sobre el lenguaje, y si la replanteamos en estos términos semánticos, sencillamente habríamos cambiado de tema. No habríamos recorrido toda la escalera semántica, sino únicamente habríamos introducido un asunto diferente, expresándonos en lo que Carnap denominó el modo formal acerca de los objetos, en lugar de hablar sobre el lenguaje. En esta concepción deflacionista, por tanto, el naturalismo del objeto comete la falacia de equivocación -un tipo de falacia uso-mención ${ }^{4}$ - en la manera en la que enuncia la cuestión que asume que es central.

Se trata de un detalle que es fácil pasar por alto porque subimos y bajamos estas escaleras semánticas con mucha facilidad. Pero si Quine está en lo cierto, la razón por la que superamos los distintos desniveles con tan poco esfuerzo es que las escaleras no conducen a ninguna parte. En nuestro caso, sin embargo, necesitamos llegar a alguna parte. Si comenzamos con una concepción lingüística de los orígenes de los problemas de la localización -si los vemos inicialmente como cuestiones acerca del uso lingüístico- entonces que lleguemos hasta una cuestión acerca de la naturaleza de objetos nolingǘsticos conlleva un auténtico cambio de enfoque teórico. Si el cambio va a ser mediado por propiedades semánticas o por relaciones de algún tipo, debe tratarse de propiedades sustantivas en el siguiente sentido: deben ser tales que al atribuirle tales propiedades a un término o a un enunciado lo que hacemos es realizar una afirmación teórica acerca de los ítems lingüísticos implicados y no usaríamos esos ítems únicamente para afirmar algo sobre otra cosa.

Cierto, estas propiedades también deben permitirnos realizar el desplazamiento hasta llegar a una cuestión sobre objetos. Nuestro enfoque teórico debe ser conducido desde una cuestión sobre los términos y los

\footnotetext{
${ }^{4}$ La falacia se sustenta en el hecho de que en la versión desentrecomilladora una expresión de la forma "'La nieve es blanca' es verdadera" contiene un uso disfrazado de mención. Si fuera una mención genuina decir que "La nieve es blanca" es verdadera no sería lo mismo que "decir que la nieve es blanca", como dice Quine. Si denominamos a esta mención desentrecomilladora mención formal, entonces una mención formal es un uso efectivo, y la falacia en este caso implica una confusión entre mención genuina y formal, o entre mención verdadera y uso efectivo.
} 
enunciados hasta una cuestión acerca de sus supuestos objetos o valores semánticos. Más aún, para la concepción naturalista del objeto del programa resultante es crucial que este desplazamiento rastree el esquema desentrecomillador (¿De qué otra manera podría una preocupación acerca del uso del término "X" conducirnos hasta un interés por el mismísimo X?) Lo que digo es que a menos que haya algo más que un simple desentrecomillado en relación con las nociones semánticas, el punto de partida no es genuinamente lingüístico y, por lo tanto, no se produciría desplazamiento alguno. (Alguien podría pensar que se trata de buenas noticias dado que, en cualquier caso, la cuestión comienza en el nivel material. Pero por ahora estamos asumiendo la concepción lingüística del origen del problema y esta respuesta está, por lo tanto, excluida.)

Entonces, dada una visión lingüística de la cuestión de la localización, las nociones semánticas sustanciales no-deflacionarias desempeñan un papel teórico crítico como fundamentos del naturalismo del objeto. Sin estas nociones no surgiría ninguna otra cuestión acerca del "lugar" natural de entidades tales como significados, causas, valores y similares. El naturalismo del objeto, así pues, depende de suposiciones teóricas sustanciales acerca de lo que los humanos hacemos con el lenguaje -brevemente: la suposición de que las relaciones semánticas sustanciales "palabra-mundo" forman parte de la mejor explicación científica de nuestro uso de los términos relevantes.

No obstante, estas suposiciones pertenecen al dominio del naturalismo del sujeto. Aún más, tal y como muestra ya la posibilidad conceptual del deflacionismo, son no-obligatorias; más sobre esto en un momento. De ahí mi Tesis de la Prioridad: dada una concepción lingǘstica del origen de los problemas de la localización, el naturalismo del sujeto es teóricamente anterior al naturalismo del objeto, y el naturalismo del objeto depende de una validación desde la perspectiva del naturalismo del sujeto.

6. ¿DEBe SER VALidado El naturalismo Del objeto? TRes RAZONES PARA SER PESIMISTAS.

Una cosa es establecer una necesidad, y otra distinta mostrar que existen razones fundadas para dudar de que esa necesidad pueda ser satisfecha. No obstante, me parece que existen sólidas razones para dudar de que el naturalismo del objeto pueda ser validado satisfactoriamente en el sentido anteriormente señalado. Estas razones son de tres tipos: 


\section{A. La amenaz̧a del deflacionista semántico.}

Ya he señalado que el deflacionismo acerca de la verdad y la referencia impide a un naturalista del objeto el acceso a la clase de escalera semántica necesaria para transformar una cuestión teórica sobre términos en una cuestión sobre sus supuestos objetos. Dados los atractivos del deflacionismo, esta es claramente razón para la preocupación desde el punto de vista del naturalismo del objeto.

Merece la pena subrayar otros dos puntos. En primer lugar, el deflacionismo posee claramente un carácter naturalista del sujeto. Ofrece una hipótesis científica en términos generales acerca de lo que criaturas lingüísticas como nosotros "hacen" con términos tales como "verdad" y "refiere" -sobre qué papel desempeñan estos términos en nuestras vidas lingüísticas-. El uso mismo de estos términos, por supuesto, comprende las bases de un problema de localización particularmente interesante. Así pues, el deflacionismo ejemplifica una aproximación del naturalismo del sujeto a un problema de la localización determinado -una aproximación que pretende explicar el uso de los términos semánticos en cuestión- y también supone un obstáculo para una construcción naturalista del objeto de los problemas de la localización en general.

En segundo lugar, merece la pena, de paso, observar de qué manera las distinciones en juego a estas alturas permiten al deflacionismo semántico evitar la acusación por parte de Paul Boghossian de que se trata de concepciones inconsistentes. ${ }^{5}$ Boghossian defiende que el irrealismo acerca de las nociones semánticas es incoherente porque el irrealismo implica, precisamente, el rechazo de que el término o la oración en cuestión tenga propiedades semánticas (un referente, condiciones de verdad). Si esta caracterización del irrealismo fuera, de hecho, obligatoria, entonces Boghossian estaría en lo cierto. El irrealismo presupone nociones semánticas $\mathrm{y}$, por lo tanto, el rechazo en cuestión es incoherente en el caso de los términos semánticos mismos.

Sin embargo este punto de vista gira en torno al hecho de que, así caracterizado, el irrealismo depende de la clase de marco teórico que ofrece la concepción representacionalista del lenguaje. Siempre que un deflacionista semántico rechace este marco teórico su postura no será incoherente. Claro está, podría insistirse que la posición resultante ya no puede ser llamada irrealismo,

\footnotetext{
${ }^{5}$ Paul Boghossian (1990; 1989).
} 
pero se trata únicamente de una cuestión terminológica. Lo realmente importante es que es incuestionablemente deflacionaria. Un deflacionista puede ofrecer, de manera consistente, una concepción aclaratoria del uso de los términos semánticos y a la vez no decir nada teóricamente significativo acerca de si estos términos "refieren" o "tienen condiciones de verdad".

Así, la respuesta al desafío que Boghossian plantea al deflacionista depende de la distinción entre negar con voz teórica que estos términos refieran o tengan condiciones de verdad (algo sobre lo que Boghossian tiene razón al señalar que un deflacionista no puede hacer); y mantener en silencio nuestra voz. teórica acerca de si estos términos refieren o tienen condiciones de verdad. Un deflacionista puede, y de hecho debe, hacer lo segundo puesto que ha expresado sus pretensiones teóricas en otros términos $-\mathrm{y}$ ha insistido, en tanto que deflacionista, en que las nociones semánticas no realizan ninguna labor interesante de aclaración causal-.

Retomaré el argumento de Boghossian en un momento ya que en mi opinión supone un problema para mis oponentes naturalistas del objeto. Por el momento, lo importante es que no supone un impedimento para un deflacionismo bien formulado.

\section{B. Elproblema de Stich.}

Hemos visto que a la luz de una concepción lingüística de los orígenes del problema de la localización, el deflacionismo semántico es incompatible con el naturalismo del objeto. En otras palabras, en la medida en la que el deflacionismo es una concepción atractiva, la "validación" del naturalismo del objeto debe ser puesta en duda.

Pero rechazar el deflacionismo no resuelve necesariamente los problemas del naturalismo del objeto. Una manera de apreciarlo es tener en cuenta las consideraciones discutidas por Stephen Stich (1996, cap. 1). En efecto, Stich defiende que es improbable que incluso una explicación científica no-deflacionaria de la referencia sea tan determinada como requiere el naturalismo del objeto para completar la tarea. La preocupación concreta de Stich es con el eliminativismo y, por tanto (en un modo lingǘ́stico), con cuestiones tales como si términos como "creencia" refieren en algún sentido. Stich argumenta que mientras mantengamos una concepción lingüística de nuestro punto de partida en metafísica, estas cuestiones inevitablemente se convierten en rehenes de las indeterminaciones en nuestra teoría de la 
referencia. Evidentemente, si Stich está en lo correcto, entonces el problema no afecta únicamente al eliminativismo. Afecta, por ejemplo, a la cuestión "¿Qué es la creencia?", tanto como afecta a la cuestión "¿Existe alguna creencia?". Por lo que tanto las respuestas realistas al problema de la localización, como las antirrealistas, se ven igualmente afectadas.

El propio Stich responde desaprobando la concepción lingüística del explanandum. Más abajo retomaremos la cuestión de si se trata realmente de una opción. Por el momento simplemente me serviré de la discusión de Stich de estas cuestiones para apoyar la siguiente conclusión tentativa. Incluso dejando a un lado la amenaza deflacionista, no está nada claro que una explicación "científica" de las relaciones semánticas vaya a suministrar lo que necesitamos para convertir una interesante cuestión sobre términos ("causación", "creencia", "bueno", etc.) en una cuestión interesante sobre objetos.

\section{C. ¿Es coherente el naturalismo del objeto?}

Hemos visto que si los problemas de la localización se originan en el nivel lingüístico, se necesitan nociones semánticas sustantivas para transformar una cuestión sobre el uso lingüístico en una cuestión acerca de objetos no lingüísticos. De esta manera el naturalismo del objeto presupone propiedades semánticas sustantivas o relaciones de alguna clase. Las dos razones previas para dudar de que el naturalismo del objeto tenga derecho a realizar esta presuposición dependían, en primer lugar, de la posibilidad del deflacionista, el cual niega que las propiedades semánticas estén cargadas en un sentido apropiado; y, en segundo lugar, de la posibilidad de que incluso una explicación científica no-deflacionaria de la referencia pueda estar forzada de manera muy imprecisa para poder ser útil como escalera semántica.

Veamos ahora una dificultad aún más seria. A la vista del hecho de que el naturalismo del objeto presupone de esta manera las nociones semánticas, es dudoso que estas nociones puedan ser investigadas consistentemente en un espíritu naturalista del objeto. El naturalismo de esta clase parece encomendado a la contingencia empírica de las relaciones semánticas. Hasta cierto punto, para cualquier término u oración es una cuestión empírica que el término refiera y si es así a qué se refiere; si tiene un hacedor de verdad y si lo tiene, dónde. No obstante, parece imposible dar sentido a esta actitud empírica con respecto a los propios términos semánticos. 
Parte de la dificultad depende de la objeción de Boghossian al irrealismo semántico. En ese contexto, el problema consistía en que si se presuponen nociones semánticas en la disputa entre realistas e irrealistas -por ejemplo, si se considera que el debate realismo/irrealismo consiste en si los términos y oraciones de un dominio determinado refieren o tienen condiciones de verdad- entonces el irrealismo acerca de estas mismas nociones es incoherente. Aquí, el problema es de la siguiente manera: en general, el proyecto del naturalismo del objeto requiere que el irrealismo sea tratado como una posibilidad empírica real; pero la propuesta de Boghossian muestra que el naturalismo del objeto no puede adoptar esta actitud con respecto a los términos semánticos.

Boghossian considera que su argumento viene a ser un argumento trascendental en favor de un realismo no naturalista acerca del contenido semántico. En mi opinión, sin embargo, es mejor verlo como un argumento pro-naturalista -pro-naturalismo del sujeto- puesto que revela una presuposición inevitablemente no naturalista en la principal concepción contemporánea de lo que significa tomarse en serio a la ciencia en filosofía. La posibilidad de esta interpretación, por supuesto, depende del hecho de que exista un naturalismo consistente alternativo que deje atrás a la típica concepción semánticamente fundada (de otra manera, también depende de una concepción lingüística del punto de partida, una concepción que estamos asumiendo en estos momentos y una concepción con la que el propio Boghossian está obviamente comprometido.)

Podría parecer implausible que pueda existir aquí un problema específico del naturalismo del objeto. Después de todo, he dado a entender que es una posibilidad empírica que la perspectiva del naturalismo del sujeto no produjera la clase de relaciones semánticas sustanciales requeridas por el naturalismo del objeto. ¿No es únicamente esta posibilidad todo lo que el naturalismo del objeto necesita para dar sentido a que sea posible el irrealismo en semántica?

No. La posibilidad empírica que hemos comentado no consiste en que el naturalismo del sujeto descubra que no existen propiedades semánticas de la clase adecuada, sino sencillamente que no encontrará ninguna razón para decir que existen. Esta es la distinción a la que apelé más arriba al explicar cómo escapa el deflacionismo a la trampa de Boghossian. La tarea básica del naturalismo del sujeto consiste en dar cuenta del uso de diferentes términos entre ellos, los propios términos semánticos- en la vida de criaturas naturales 
en un entorno natural. La distinción mencionada hace posible que al completar esta tarea, el naturalista del sujeto sencillamente pueda encontrarse con que no es necesaria una categoría aclaratoria de las propiedades y relaciones semánticas. (En ningún punto necesitaría decir que el término "refiere" refiere o no refiere algo, por ejemplo, excepto en el sentido no deflacionario, no teórico.) Desde la perspectiva del naturalista del objeto, claro está, esto tiene toda la pinta de ser una investigación sobre si hay propiedades semánticas, pero el naturalismo del sujeto carece de razones para construirlo de esa manera. En realidad tiene una muy buena razón para no construirlo de esa manera si, como ha argumentado Boghossian, esta construcción es sencillamente incoherente.

La cuestión de la coherencia de la aproximación del naturalista del objeto a los términos semánticos es sutil y difícil, y no pretendo haber demostrado que la dificultad sea concluyente. Lo que espero haber establecido es algo más débil. Un naturalista no tiene ni la necesidad ni el derecho automático a una explicación sustancial de las relaciones semánticas entre palabras o pensamientos y el resto del mundo natural -ningún derecho automático porque, según el propio naturalismo, se trata como mucho de una cuestión empírica; y ninguna necesidad porque hay maneras de ser naturalista que no dependen de esa suposición. Con todo, la tesis más fuerte, la tesis de la incoherencia, me parece fascinante y plausible, y quiero mencionar brevemente otra manera de desarrollar la dificultad.

Si hay una explicación naturalista del objeto coherente de las relaciones semánticas entonces, como señalamos con anterioridad, el naturalista del objeto querrá decir que la explicación correcta no es a priori-existe más de una posibilidad coherente, y la cuestión es en parte una cuestión empírica-. Consideremos únicamente dos de las posibilidades coherentes -por ejemplo, dos explicaciones rivales de la referencia-. La primera explicación dice que la referencia es la relación natural $\mathrm{R}^{*}$; la segunda explicación que es la relación natural $\mathrm{R}^{* *}$. Así pues, aparentemente tenemos dos visiones incompatibles de lo que es realmente la referencia.

Pero, ¿las tenemos? Pensemos con un poco más de detenimiento acerca de cada una de estas afirmaciones. La primera explicación afirma que el término ordinario "Referencia" elige, o se refiere, a la relación $\mathrm{R}^{*}$. En otras palabras, que

"Referencia” en la relación $\mathrm{R}^{*}$ está por $\mathrm{R}^{*}$ 
La segunda explicación afirma que el término ordinario "Referencia" elige, o se refiere, a la relación $\mathrm{R}^{* *}$. En otras palabras, que

"Referencia” en la relación $\mathrm{R}^{* *}$ está por $\mathrm{R}^{* *}$

¿Son incompatibles estas afirmaciones? De ninguna manera. El término "Referencia" puede perfectamente estar en estas dos relaciones diferentes por dos cosas diferentes, incluso si permitimos (tal y como los proponentes de ambas concepciones querrán insistir) que en el caso de cada relación por separado, ningún término podría estar en esa relación por ambos.

Nuevamente, el problema surge a partir hecho de que el naturalista del objeto está tratando de hacer una pregunta que convierte en inestables a sus presuposiciones. No hay ninguna pregunta fija con distintas respuestas sino, por así decir, diferentes preguntas para cada respuesta. Dejo aquí a modo de ejercicio otro puzle de esta clase. Se trata de una pregunta con varias respuestas:

La opción seleccionada abajo es:
A. Opción A
[ ]
B. Opción B
C. Opción C
[ ]
D. Ninguna de las anteriores
[ ]

El problema no es que no haya una respuesta correcta, sino que hay demasiadas respuestas correctas. ${ }^{6}$ De nuevo, el resultado parece ser que, a la luz del papel de las nociones semánticas en la concepción del naturalista del objeto sobre la tarea de la filosofía, esa tarea no tiene sentido con respecto a los términos semánticos propiamente dichos.

\section{7. ¿RESIDE EL PROBLEMA EN LA CONCEPCIÓN LINGÜÍSTICA DEL EXPLANANDUM?}

\footnotetext{
${ }^{6}$ En un examen más detallado de estas cuestiones, sería interesante tener en cuenta la conexión entre esta clase de consideración (y también el argumento de Boghossian) y las preocupaciones de Putnam (su "solo más teoría") acerca del uso metafísico de una teoría de la referencia (Putnam, 1978; 1981).
} 
Tal y como he subrayado, la discusión anterior ha asumido una concepción lingüística de los orígenes del problema de la localización. ¿Se trata de una suposición optativa?¿Puede una concepción material sacar al naturalismo del objeto del apuro? Concluyo con dos razones para ser escéptico a este respecto.

\section{A. El gato está fuera de la bolsa.}

Esta claro que la concepción lingüística de la cuestión de la localización ya está en juego. Comenté con anterioridad que tratar al no-cognitivismo como una opción en estos debates equivale a comprometerse con una concepción lingüística del origen del problema. La amenaza al naturalismo del objeto parte de este punto, reparando en que el supuesto representacionalista no es obligatorio -que existen otras posibles aproximaciones teóricas al lenguaje en las que las nociones semánticas no desempeñan ningún rol significativo-. Hemos ofrecido, por lo tanto, la posibilidad de una concepción naturalista (del sujeto) de los aspectos relevantes del habla y del pensamiento humanos desde una perspectiva en la que la cuestión material (“¿Qué son las Xs?") sencillamente no surge. ${ }^{7}$ En este nivel la única manera que un naturalista del objeto tiene de recuperar el control de la pelota consiste en defender el supuesto representacionalista (un proyecto lleno de dificultades por las razones apuntadas arriba).

¿No podría un naturalista del objeto desafiar la presente concepción acerca del punto de partida? ¿Qué es lo que es erróneo en la propuesta de Stich, que comenzamos en el nivel material y hacemos metafísica sin soportes semánticos? Pienso que lo que está mal en este caso es que lo que propone es que debemos sencillamente ignorar la posibilidad de que la filosofía pueda tener algo que aprender de la reflexión naturalista - naturalista del sujeto- acerca de las cosas que los seres humanos hacemos con el lenguaje. (Si esto parece

\footnotetext{
${ }^{7}$ Esto es, no surge como cuestión provocada por el naturalismo. Claro está que tales cuestiones surgen en otros muchos contextos - ¿Que es la justicia?”, “¿Qué es la ironía?”, “¿Qué es la pasta?”, por ejemplo-. Si ciertas preguntas más o menos comunes de este tipo dan lugar a rompecabezas de la clase de los del naturalismo del objeto, el naturalista del sujeto recomienda una dosis de terapia lingüística: piensa detenidamente acerca de tus supuestos sobre el lenguaje antes de dejarte convencer de que existe algún rompecabezas ontológico genuino.
} 
controvertido, reparemos en que sería como ignorar la posibilidad del nocognitivismo). Por lo tanto se trata de un movimiento radicalmente antinaturalista. Para alguien que se toma la ciencia seriamente, el único camino que lleva hasta el naturalismo del objeto es el camino difícil: conceder que el problema tiene su origen en el nivel lingüístico y defender la concepción representacionalista.

\section{B. Las nociones semánticas forman parte de la caja de herramientas de la metafísica} moderna

La segunda consideración merece un análisis mucho más detallado del que puedo llevar a cabo aquí. Brevemente, da la sensación de que las nociones semánticas tales como referencia y verdad se han convertido en instrumentos del programa de investigación de la metafísica contemporánea. Es práctica común identificar nuestros objetos de interés de manera semántica -como hacedores de verdad o referentes, pongamos por caso, o de manera más general, como "desempeñantes" de roles semánticos-.

No obstante, la relevancia de esta observación acerca de la práctica filosófica dista mucho de estar clara. Una de las dificultades consiste en decidir cuáles de los muchos usos de esas nociones semánticas son usos teóricos "sustanciales", y cuáles pueden ser tomados de un modo meramente quineano -usos convenientes, aunque teóricamente inocuos, de términos semánticos deflacionarios-. Debido a las razones discutidas anteriormente, el uso de nociones semánticas deflacionarias en metafísica no es incompatible con la concepción material de los orígenes de la cuestión de la localización. Pero si hay nociones más sustantivas en juego, entonces el dominio lingüístico también parece jugar un papel más significativo. Afirmaciones relativas al lenguaje pasan adquieren un rol análogo al de los datos observacionales en ciencia, con las relaciones semánticas sustentando inferencias sobre una realidad oculta. Así, la empresa se compromete con una concepción lingüística de su punto de partida.

Hay muchos cabos en esta reinstrumentalización de la metafísica contemporánea -el Retorno de la Lingüística, podríamos llamarla-. Creo que un cabo importante es el siguiente. En la influyente concepción de la 
identificación teórica en ciencia a cargo de David Lewis, ${ }^{8}$ los objetos que son de interés se identifican en tanto que ocupantes de roles causales. Si el término teórico " $\mathrm{X}$ " es definido de esta manera, entonces sabemos lo que tenemos que hacer para responder a la pregunta "¿Qué es X?”. Experimentamos en el laboratorio que es el mundo, ajustando esto, girando aquello otro, hasta que descubrimos qué es lo que realiza el trabajo causal que nuestra teoría asigna X.

En opinión de muchos otros, sin embargo, el programa de Lewis no sólo es adecuado para la ciencia, sino también para la metafísica. ${ }^{9}$ De hecho, algunos de los que así piensan rechazarán la sugerencia, implícita en mi formulación, de que la metafísica es diferente de la ciencia. Pero existe al menos una diferencia. En metafísica no hay garantía de que nuestros objetos de interés sean de la clase de cosa que tienen roles causales. Podemos estar interesados en números, o en valores, o en la causación misma y para todas estas cosas es cuando menos controvertido si pueden ser identificadas como la causa de esto o el efecto de aquello otro. ${ }^{10}$

Así pues, en el programa global, el lugar de la causación debe ser ocupado por otra cosa. ¿Qué otra cosa podría ser? me parece que existen dos posibilidades. Una es que los roles causales sean reemplazados por roles semánticos. En este caso el procedimiento para responder una pregunta de la forma “¿Qué es X?” es análogo al descrito arriba, excepto en que el objetivo de nuestros experimentos -conceptuales en esta ocasión antes que experimentales- es descubrir, por así decir, a qué se refiere el término "X", o qué es lo que convierte en verdadera a la afirmación de que X es $\mathrm{F}$.

\footnotetext{
${ }^{8}$ David Lewis (1972; 19970).

${ }_{9}^{9}$ Véase concretamente Jackson (1998).

${ }^{10}$ La afirmación de que la metafísica se extiende más allá del reino de la causación es probablemente más controvertida de lo que yo doy a entender aquí. Cualquiera que lo rechace estará inclinado a decir que donde acaba la causación, comienzan modos filosóficos no metafísicos: el formalismo, quizás, en el caso de las matemáticas, el no-cognitivismo en el caso de la teoría de los valores, etc. Para nuestros objetivos aquí basta señalar que esta opinión está sujeta a una concepción lingüística de la cuestión de la localización, ya que la naturaleza de estas concepciones es lingüística. No obstante, merece la pena reparar en que en una metafísica de esta clase causalmente fundamentada, la noción de causación será con mucha probabilidad problemática de una manera análoga a como lo son las nociones semánticas en una naturalismo del objeto lingüísticamente fundamentado. Se trataría de una noción primitiva, inaccesible para los propios métodos declarados por el programa.
} 
Esa es la primera posibilidad: que las relaciones semánticas desempeñen el mismo rol sustantivo en el programa general que el que las relaciones causales desempeñaron en el programa original. Si es así, entonces el resultado es el que hemos visto. El lenguaje se ha convertido en el punto de partida de la metafísica y la posición resultante es vulnerable de la manera descrita arriba.

La segunda posibilidad es que nada específico reemplace a la causación. Simplemente depende del caso particular, en lo que el método Ramsey-Lewis nos dice finalmente acerca de la X en cuestión. Es posible que figuren términos semánticos en la descripción de la tarea, pero en esta segunda posibilidad son deflacionarios. Decimos: "X es lo que hace que esta Ramsey-oración sea verdadera", pero se trata únicamente de un modo conveniente de hacer lo que podríamos hacer diciendo "X es la cosa tal que..." y a continuación usar la Ramsey-oración en cuestión.

Opino que esta segunda versión evita un uso esencial de nociones semánticas no deflacionarias y es, por lo tanto, compatible con una concepción material de nuestro punto de partida en metafísica. El problema es que a partir de ahí se separa de cualquier argumento general a favor del naturalismo (del objeto), de una clase que iría en paralelo con el argumento de Lewis a favor del fisicalismo acerca de lo mental. ${ }^{11} \mathrm{El}$ argumento de Lewis descansa sobre la premisa de que toda causación es causación física -0 , como lo expresa Lewis, la suposición de "la adecuación explicativa de la física"-. Sin esta premisa claramente no hay nada que nos lleve desde la conclusión de que un estado mental $\mathrm{M}$ tiene un determinado rol causal a la conclusión de que $\mathrm{M}$ es un estado físico. El problema para la segunda de las dos versiones del programa generalizado de Lewis es que sin nada que desempeñe el rol que la causación desempeña en el programa restringido, no habrá nada similar a esta premisa crucial en apoyo de un argumento generalizado a favor del fisicalismo.

Así, me parece que los naturalistas del objeto se enfrentan a un dilema. Si apelan a relaciones semánticas sustantivas tienen ante sí un posible argumento a favor del naturalismo expresado en términos de esas relaciones por ejemplo, el argumento de que todas las verdades tienen hacedores de verdad naturales-. En este caso, sin embargo, están implícitamente comprometidas con una concepción lingüística de los "datos brutos" de estas

${ }^{11}$ David Lewis (1966). 
investigaciones, y se enfrentan a los problemas identificados con anterioridad. Si no apelan a relaciones semánticas sustantivas, evitan estas dificultades, pero pierden los recursos teóricos con los que formular un argumento general a favor del naturalismo concebido en el modelo naturalista del objeto.

Sin la protección de ese argumento, el contrincante difícil no es alguien que accede a jugar el juego en el modo material y que juega para el nonaturalismo. El contrincante difícil es el naturalista que saca ventaja de una perspectiva teórica no-representacionalista para evitar por completo el modo material. Si un contrincante de esta naturaleza puede explicar porqué unas criaturas naturales en un entorno natural han llegado a bablar de maneras tan variadas -sobre la "verdad", los "valores", el "significado", la "causación" y el resto-, ¿qué incógnita queda por resolver?, ¿cuál es la deuda que tiene ahora la filosofía con la ciencia?

En resumidas cuentas, es dudoso que un naturalista del objeto pueda evitar una concepción lingüística de la cuestión de la localización y, por lo tanto, escapar de las dificultades identificadas con anterioridad. En todo caso, algunas versiones del naturalismo del objeto se sirven de la concepción lingüística para poner a trabajar a las relaciones semánticas al servicio de la metafísica. En otros casos, la inescapabilidad de la concepción lingüística depende de un hecho que está siempre disponible para el contrincante del naturalista del objeto, el naturalista del sujeto, en tanto que la base de una concepción alternativa de cuál es la tarea de la filosofía en estos casos. El instinto del naturalista del objeto es siempre el de apelar al carácter representacional del lenguaje para devolver la cuestión al nivel material; pero esto, como hemos visto, es la receta de una gran incomodidad.

\section{Pluralidad Natural.}

Lingüísticamente construido, el problema de la localización nace de la sorprendente multiplicidad del lenguaje ordinario, una asombrosa pluralidad del temas de discurso. Dada una concepción naturalista de los hablantes, la suma de una concepción representacionalista del discurso hace que la interpretación ontológica del naturalismo del objeto del problema de la localización sea casi irresistible. Término a término, oración a oración, tópico a tópico, la escalera semántica representacionalista nos conduce desde el lenguaje hasta el mundo, desde las palabras a sus objetos mundanos. De alguna manera, la multiplicidad resultante de clases de entidades -valores, modalidades, 
significados y todo lo demás- necesita ser acomodado en el dominio natural. ¿Con qué otra cosa, después de todo, podrían estar relacionados los hablantes naturales por medio de sus relaciones semánticas naturales?

No obstante, sin una concepción representacionalista del habla, el rompecabezas adopta una forma muy diferente. Permanece en el dominio lingüístico, un rompecabezas acerca de la pluralidad de modos de habla, de formas de comportamiento lingüístico. El desafío, ahora, es sencillamente explicar en términos naturalistas cómo criaturas como nosotros han llegado a hablar de todas estas maneras. Es cuestión de explicar que rol desempeñan los diferentes juegos del lenguaje en nuestras vidas -qué diferencias existen entre las funciones de hablar de valores y de las funciones de hablar de electrones, por ejemplo-. Esto ciertamente requiere pluralidad en el mundo, pero de una clase familiar, en un lugar familiar. Nadie espera que el comportamiento humano no sea altamente complejo. Sin el representacionalismo, las junturas entre tópicos siguen siendo junturas entre clases de comportamientos, y no necesitan verse reflejadas en ninguna ontología de cualquier otra clase.

Lo que es importante para nuestros objetivos actuales es, por una parte, que se trata de un proyecto reconociblemente naturalista y, por otra parte, que se trata de un proyecto muy diferente a los de la mayoría de naturalistas filosóficos contemporáneos. He defendido que la concepción popular (el naturalismo del objeto) tiene sus propios problemas debido a sus supuestos semánticos. La disponibilidad de la alternativa naturalista del sujeto deja claro que los problemas del naturalismo del objeto no son problemas del naturalismo per se-no son un desafío para la opinión de que en algunas áreas, la filosofía remite debidamente a la ciencia.

Empezamos con la relevancia de la ciencia para la filosofía. Finalicemos con la relevancia de la ciencia para la propia ciencia. El naturalismo del objeto no sólo cede a la ciencia el centro del escenario, sino todo el escenario, haciendo que el conocimiento científico sea el único conocimiento que existe (al menos en cierto sentido). El naturalismo del sujeto sugiere que la ciencia podría adoptar sin mayores problemas una visión más modesta de su propia importancia. Se imagina que es un descubrimiento científico que la ciencia no es todo lo que existe -que la ciencia es únicamente una de las muchas ${ }^{12}$ cosas

12 O más probablemente, me parece, "varias cosas entre muchas", en el sentido de que el lenguaje científico mismo no es monofuncional. Opino que el discurso causal y modal tiene 
que hacemos con el discurso "representacional"-. Si es así, entonces las suposiciones semánticas del naturalismo del objeto son mala ciencia, el legado de una ciencia insuficientemente naturalista. La historia, entonces, tiene la siguiente moraleja: si hacemos mejor ciencia en filosofía, estaremos menos inclinados a pensar que la ciencia es lo único que existe.

Huw Price

University of Cambridge

hp331@cam.ac.uk

\section{REFERENCES}

Boghossian, P. (1989), “The Rule-Following Considerations”, Mind 98, pp. 507-549. Boghossian, P. (1990), “The Status of Content”, Philosophical Review, 99, pp. 157-184. JACKSOn, F. (1998), From Metaphysics to Ethics, Oxford: Clarendom Press.

LEWIS, D. (1966), “An Argument for the Identity Theory”, Journal of Philosophy, 63, pp. $17-25$

LEWIS, D. (1970), "How to Define Theoretical Terms", Journal of Philosophy, 67, pp. $427-46$.

LEWIS, D. (1972), "Psychophysical and Theoretical identifications", Australasian Journal of Philosophy, 50, pp. 249-58.

Price, H. (1992), “Metaphysical Pluralism”, Journal of Philosophy, 89, pp. 387-409.

PrICE, H. (1997), "Naturalism and the Fate of the M-worlds", Proceedings of the Aritotelian Society, Supplementary Volume, LXXI, pp. 247-267.

Putnam, H. (1978), Meaning and the moral Sciences, Boston: Routledge and Kegan Paul.

Putnam, H. (1981), Reason, Truth and History, New York: Cambridge University Press.

Quine W. V. O. (1970), Filosofía de la lógica, Prentice-Hall.

STICH, S. (1996), Deconstructing the Mind, New York: OUP.

distintas funciones en este sentido, y, si bien es esencial para cualquier ciencia interesante, no es toda la historia. Si es así, esto es suficiente para mostrar que existe una pluralidad funcional dentro del lenguaje científico y fuera de él. Para saber más sobre este asunto y el programa aquí apenas esbozado, véase Price (1997 y 1992). 